\title{
A study to identify the prevalence of vulvovaginal candidiasis in second trimester
}

\author{
Rashmi Kruthipati, Radhika Chethan, Anitha Gabbalkaje Shiva*, Sukanya Suresh
}

Department of Obstetrics and Gynaecology, Bangalore Medical College and Research Institute, Bangalore, Karnataka, India

Received: 09 June 2021

Accepted: 24 June 2021

\section{*Correspondence:}

Dr. Anitha Gabbalkaje Shiva,

E-mail: aninaik85@gmail.com

Copyright: $\odot$ ( the author(s), publisher and licensee Medip Academy. This is an open-access article distributed under the terms of the Creative Commons Attribution Non-Commercial License, which permits unrestricted non-commercial use, distribution, and reproduction in any medium, provided the original work is properly cited.

\section{ABSTRACT}

Background: Vaginal candidial infections are due to excessive growth of Candida. These are normally present in the vagina in small numbers. Vaginal infections are typically caused by the yeast species Candida albicans. It is found that candidial infection increases the risk of preterm labour. Aims and objectives of the study were to determine the prevalence of vulvovaginal candidiasis and influence of maternal age, parity and weeks of 2 nd trimester on its occurrence among pregnant women in $2^{\text {nd }}$ trimester, attending the antenatal clinic in our hospital.

Methods: A prospective study conducted in BMCRI for a period of 3 months (October 2019-December 2019) on patients in second trimester. Consent of patients taken. High vaginal swabs were collected from the pregnant patients in second trimester and sent for culture. Candida positive cases were noted and results were analysed.

Results: A total of 100 high vaginal swabs were collected and reported in our study. Among them 54 swabs were positive for Candida growth (54\%) and 46 swabs were negative for growth (46\%). Culture positive patients' clinical details were analysed and tabulated.

Conclusions: Our study concluded that candidiasis is more prevalent in pregnant women but there was no statistical significance in occurrence of vaginal candidiasis among various age groups, parity or trimester. Hence it is better to screen all the patients in I early II trimester in order to find out and treat positive cases early to prevent preterm births attributed to vaginal candidiasis.

Keywords: Preterm birth, Pregnancy, Vulvovaginal candidiasis, Candida albicans, Candidial infection

\section{INTRODUCTION}

Candida is the leading cause of vaginitis, and $75 \%$ of women have at least one episode in their lifetimes. ${ }^{1,2}$ Pregnancy is a predisposing factor for vulvovaginal candidiasis. ${ }^{3-5}$ During pregnancy, there is an increase in progesterone and oestrogen levels, especially in the last trimester. ${ }^{6-8}$ Progesterone has an inhibitory effect on the anti-Candida activity of neutrophils. ${ }^{6}$ On the other hand, oestrogen reduces the ability of vaginal epithelial cells to inhibit the growth of Candida albicans on them. ${ }^{9}$ However, about $75 \%$ of women generally harbour this fungus without it causing harm to them. ${ }^{10-12}$ During normal pregnancy, candidiasis is frequently encountered without significant risk for the foetus. Nevertheless, pregnancy may be negatively affected by vulvovaginal candidiasis. If untreated, vaginal candidiasis can lead to chorioamnionitis with subsequent abortion and prematurity in pregnant women, congenital infection of the neonate and pelvic inflammatory disease (PID) resulting in infertility in nonpregnant women. ${ }^{12}$ Vulvovaginal candidiasis could be a risk factor for candidemia in preterm neonates during normal pregnancy. Amongst Candida species isolated from vaginal specimens, $C$. albicans is the most predominant, followed by other non-albicans Candida (NAC) such as C. glabrata, C. tropicalis, $C$. dubliniensis and C. krusei. ${ }^{13-15}$ There is an emerging evidence that eradication of Candida during pregnancy may decrease the risk of preterm births and late miscarriages. If preterm births are reduced significantly, it 
will be reflected in reduction of the need of the neonatal facilities, hospitalization and prolonged care for preterm babies. In addition, it also reduces the financial burden for the patients and health sectors.

\section{Aims and objectives}

Aims and objectives of the study were to determine the prevalence of vulvovaginal candidiasis and influence of maternal age, parity and weeks of $2^{\text {nd }}$ trimester on its occurrence among pregnant women in $2^{\text {nd }}$ trimester, attending the antenatal clinic in our hospital.

\section{METHODS}

A prospective study conducted in BMCRI over a period of 3 months from the October 2019 to December 2019. The study population was selected from the patients who were attending the antenatal outpatient department after getting the detailed informed consent. patients in second trimester were included. A detailed clinical history was taken from the patients; age, parity, presence or absence of symptoms (vaginal discharge, itching or burning) and risk factors (diabetes, use of antibiotics in the past, previous history of candidiasis and history of immunosuppression) associated with vaginal candidiasis were recorded. Under sterile precautions high vaginal swabs were taken, placed immediately in the case, labelled and sent to department of microbiology for growth In Candida positive cultures, Candida albicans or nonalbicans were differentiated and recorded. Growth results were recorded with patient details. The results were statistically analysed and tabulated.

\section{Inclusion criteria}

Patients in second trimester, patients consenting to the study, patients with or without symptoms of candidiasis were included in the study.

\section{Exclusion criteria}

Patients not consenting to the study and patients in first or third trimester were excluded from the study.

\section{RESULTS}

\section{Age distribution}

Majority of patients were in age group between 26-30 years. Least belonged to group $>35$ years. 42 patients were of group 20-25 years. 31-35 years group had 12 patients.

Table 1: Age distribution.

\begin{tabular}{|l|l|}
\hline Age (years) & No. of patients \\
\hline $\mathbf{2 0 - 2 5}$ & 42 \\
\hline $\mathbf{2 6 - 3 0}$ & 44 \\
\hline $\mathbf{3 1 - 3 5}$ & 12 \\
\hline $\mathbf{3 5}$ & 2 \\
\hline
\end{tabular}

\section{Parity}

Gravida 2 was the most common parity on our study. Next common group was primi. Lowest was G3 and G4.

Table 2: Parity.

\begin{tabular}{|l|l|}
\hline Parity & No. of patients \\
\hline Primi & 23 \\
\hline G2 & 55 \\
\hline G3 & 16 \\
\hline G4 and above & 6 \\
\hline
\end{tabular}

\section{Socio economic status}

Most of our study patients belonged to middle class. Lower class were 13 . Very few patients were from the upper class.

Table 3: Socio economic status.

\begin{tabular}{|l|l|}
\hline Socio economic status & No. of patients \\
\hline Upper & 18 \\
\hline Middle & 69 \\
\hline Lower & 13 \\
\hline
\end{tabular}

\section{Period of gestation}

Most of our patients in the study were in the $18+1-22$ weeks $(40 \%)$, next common group was $22+1-28$ weeks (36\%). $24 \%$ was contributed by $14+1-18$ weeks.

Table 4: Period of gestation.

\begin{tabular}{|c|c|}
\hline $\begin{array}{l}\text { Period of gestation } \\
\text { (Weeks) }\end{array}$ & No. of patients \\
\hline $14+1-18$ & 24 \\
\hline $18^{+} 1-22$ & 40 \\
\hline $22^{+} 1-28$ & 36 \\
\hline
\end{tabular}

\section{Number of patients with symptoms}

Most of our patients were asymptomatic $77 \%$.

Table 5: Number of patients with symptoms.

\begin{tabular}{|ll|}
\hline Variables & No. of patients \\
\hline Symptom's present & 23 \\
\hline Symptom's absent & 77 \\
\hline
\end{tabular}

\section{Common symptoms}

Itching and curdy white discharge was the most common symptoms. Foul smell and burning sensation were the other few symptoms.

\section{Culture results}

Majority of the cultures were positive for candidial growth 
Table 6: Common symptoms.

\begin{tabular}{|l|l|}
\hline Common symptoms & No. of patients \\
\hline Itching & 8 \\
\hline Curdy white discharge & 7 \\
\hline Burning sensation & 5 \\
\hline Foul smell & 3 \\
\hline
\end{tabular}

Table 7: Culture results.

\begin{tabular}{|ll|}
\hline $\begin{array}{l}\text { Total no. of } \\
\text { patients }\end{array}$ & Culture result \\
\hline $\mathbf{5 4}$ & Positive \\
\hline $\mathbf{4 6}$ & Negative \\
\hline
\end{tabular}

\section{Distribution of vaginal candidiasis among different age groups}

In our study, the highest number of positive cases were found to be in 26-30 years of age group (51\%) followed by 20-25 years $(24 \%)$. 31-35 years and $>35$ years were almost the same $(11 \%)$.

Table 8: Distribution of vaginal candidiasis among different age groups.

\begin{tabular}{|l|l|}
\hline Age (years) & No. of patients \\
\hline $\mathbf{2 0 - 2 5}$ & 13 \\
\hline $\mathbf{2 6 - 3 0}$ & 28 \\
\hline $\mathbf{3 1 - 3 5}$ & 6 \\
\hline $\mathbf{3 5}$ & 7 \\
\hline
\end{tabular}

\section{Distribution of vaginal candidiasis in relation to parity}

Primi and G2 were almost the same in distribution $(38.8 \%)$. G3 had (10\%) of distribution.

Table 9: Distribution of vaginal candidiasis in relation to parity.

\begin{tabular}{|l|l|}
\hline Parity & No. of patients \\
\hline Primi & 20 \\
\hline G2 & 21 \\
\hline G3 & 12 \\
\hline G4 and above & 1 \\
\hline
\end{tabular}

\section{Distribution of vaginal candidiasis in second trimester}

The 22+1-28 weeks had most distribution of cases (68\%).

Table 10: Distribution of vaginal candidiasis in second trimester.

\begin{tabular}{|l|l|}
\hline $\begin{array}{l}\text { Distribution of cases } \\
\text { (Weeks) }\end{array}$ & No. of patients \\
\hline $\mathbf{1 4 + 1 - 1 8}$ & 8 \\
\hline $\mathbf{1 8}+\mathbf{1 - 2 2}$ & 9 \\
\hline $\mathbf{2 2 + 1 - 2 8}$ & 37 \\
\hline
\end{tabular}

\section{DISCUSSION}

Pregnant women have 2-fold increases in prevalence of vaginal candidiasis when compared to nonpregnant women. ${ }^{16}$

Vulvovaginal candidiasis is an important cause of morbidity in pregnancy which can result in miscarriages, Candida chorioamnionitis, subsequent preterm delivery and emotional stress. ${ }^{17,18}$

In our study, the highest number of positive cases were found to be in 26-30 years of age group (51\%) followed by 20-25 years (24\%). 31-35 years and $>35$ years were almost the same $(11 \%)$.

In relation to parity, primi and $\mathrm{G} 2$ were almost the same in distribution $(38.8 \%)$. G3 had $(10 \%)$ of distribution. In relation to $2^{\text {nd }}$ trimester, in our study, the highest number of positive cases were found to be in 26-30 years of age group $(51 \%)$ followed by $20-25$ years $(24 \%)$. 31-35 years and $>35$ years were almost the same (11\%). 22+1-28 weeks had the most distribution of cases $(68 \%)$.

$23 \%$ of Candida positive women were symptomatic and the remaining $77 \%$ were asymptomatic.

As preterm labour is a result of chronic inflammatory process, it is better to screen all patients in early/mid II trimester to pick up the cases early to initiate the treatment. The safety of any proposed intervention in pregnancy is of great importance. Clotrimazole is classified as category a drug, which has been used by large number of pregnant women without any proven increase in the frequency of malformation or harmful effects on the fetus. ${ }^{19,20}$

Local application of clotrimazole vaginal passerines or cream is generally well tolerated, can be used for 6 days which is supported by the Cochrane systematic review of treatment for Candida eradication in pregnancy and was the regimen used in the kiss trial. ${ }^{21}$ As there is a high prevalence of vaginal candidiasis in pregnancy and its associated complications, it is better to screen all pregnant women and treat the positive patients.

\section{CONCLUSION}

Early detection and diagnosis may improve the clinical condition of the pregnant women and reduces the number of preterm term births significantly. If preterm births are reduced significantly, it will be reflected in reduction of the need of the neonatal facilities, hospitalisation and prolonged care for preterm babies. In addition, it also reduces financial burden for patients and health sectors.

Funding: No funding sources

Conflict of interest: None declared

Ethical approval: The study was approved by the Institutional Ethics Committee 


\section{REFERENCES}

1. Sobel J. Vaginal infections in adult women. Med Clin N Am. 1990;74(6):1573-602.

2. Sobel JD, Faro S, Force RW, Foxman B, Ledger WJ, Nyirjesy PR et al. Vulvovaginal candidiasis: epidemiologic, diagnostic, and therapeutic considerations. Am J Obstet Gynecol. 1998;178(2):203-11.

3. Sobel JD. Vulvovaginal candidosis. Lancet. 2007;369(9577):1961-71.

4. Ahmad A, Khan AU. Prevalence of Candida species and potential risk factors for vulvovaginal candidiasis in Aligarh, India. Eur J Obstet Gynecol Reprod Biol. 2009; 144(1):68-71.

5. Fidel P. Host defense against oropharyngeal and vaginal candidiasis: site-specific differences. Rev Iberoam Micol. 1999;16:8-15.

6. Fidel P. Host defense against oropharyngeal and vaginal candidiasis: site-specific differences. Rev Iberoam Micol. 1999;16:8-15.

7. Bauters TG, Dhont MA, Temmerman MI, Nelis HJ. Prevalence of vulvovaginal candidiasis and susceptibility to fluconazole in women. Am J Obstet Gynecol. 2002;187(3):569-74.

8. Nelson M, Wanjiru W, Margaret MW. Prevalence of vaginal candidiasis and determination of the occurrence of Candida species in pregnant women attending the antenatal clinic of Thika District hospital. Kenya Open J Med Microbiol. 2013;3(4):264.

9. Fidel PL, Cutright J, Steele C. Effects of reproductive hormones on experimental vaginal candidiasis. Infect Immun. 2000;68(2):651-7.

10. Ellepola A, Samaranayake L. The effect of limited exposure to antimycotics on the relative cell-surface hydrophobicity and the adhesion of oral Candida albicans to buccal epithelial cells. Arch Oral Biol. 1998;43(11):879-87.

11. Ellepola A, Samaranayake L. The effect of limited exposure to antimycotics on the relative cell-surface hydrophobicity and the adhesion of oral Candida albicans to buccal epithelial cells. Arch Oral Biol. 1998;43(11):879-87.
12. Oviasogie F, Okungbowa F. Candida species amongst pregnant women in Benin city, Nigeria: effect of predisposing factors. Afr J Clin Exp Microbiol. 2009;10(2):92-8.

13. Abruquah $\mathrm{H}$. Prevalence and antifungal susceptibility of Candida species isolated from women attending a gynaecological clinic in Kumasi, Ghana. J Sci Technology (Ghana). 2012;32(2):39-45.

14. Feglo P, Narkwa P. Prevalence and antifungal susceptibility patterns of yeast isolates at the Komfo Anokye teaching hospital (KATH), Kumasi, Ghana. 2012.

15. Sasikala G, Agatha D, Janagond BA, Thenmozhivalli PR. Characterization of Candida and its antifungal susceptibility pattern from patients with vaginal candidiasis in a Tertiiary care hospital in South India. J Pharmaceutical Biomed Sci. 2013;30(30):51-6.

16. Guideline vulvovaginal candidiasis of the German Society for Gynecology and Obstetrics, the Working Group for Infections and Infect immunology in Gynecology and Obstetrics, the German Society of Dermatology, the Board of German Dermatologists and the German Speaking Mycological Society. Mycoses. 2012;55(3):1-13.

17. Morrison EA, Cushman LF. Prevention of preterm delivery. N Engl J Med. 2007;357(19):1979.

18. Singh SI. Treatment of vulvovaginal candidiasis. Clin. Rev. CPJ/RPC. 2014;136(9):26-30.

19. Nurat AA, Babalola GO, Shittu MO. Detection and Epidemiology of Vulvovaginal Candidiasis among Asymptomatic Pregnant Women Attending a Tertiary Hospital in Ogbomoso, Nigeria. Int J Biomed Res. 2015;6(7).

20. Czeizel AE, Tóth M, Rockenbauer M. No teratogenic effect after clotrimazole therapy during pregnancy. Epidemiology. 1999;10(4):437-40.

21. Rosa FW, Baum C, Shaw M. Pregnancy outcomes after first-trimester vaginitis drug therapy. Obstet Gynecol. 1987;69(5):751-5.

Cite this article as: Kruthipati R, Chethan R, Shiva AG, Suresh S. A study to identify the prevalence of vulvovaginal candidiasis in second trimester. Int $\mathrm{J}$ Reprod Contracept Obstet Gynecol 2021;10:2647-50. 